\title{
A de novo mutation of SALL4 in a Chinese family with Okihiro syndrome
}

\author{
XIULI MA ${ }^{1 *}$, RUI HUANG ${ }^{1 *}$, GUO LI $^{1}$, TIESONG ZHANG ${ }^{1}$ and JING MA ${ }^{1,2^{*}}$ \\ ${ }^{1}$ Department of Otolaryngology, Head and Neck Surgery, Kunming Children's Hospital; \\ ${ }^{2}$ Kunming Key Laboratory for Prevention and Control of Congenital Birth Defects of \\ Children, Kunming, Yunnan 650228, P.R. China
}

Received December 20, 2021; Accepted January 28, 2022

DOI: $10.3892 / \mathrm{mmr} .2022 .12647$

\begin{abstract}
Okihiro syndrome is an autosomal dominant condition characterized by Duane anomaly and radial ray defects. The present study aimed to analyze the clinical manifestations of a patient with Okihiro syndrome and perform genetic testing on the proband and his family to determine the biological pathogenesis. Clinical data were collected from the proband and his family and genomic DNA was extracted from peripheral blood. Whole exome sequencing was performed by high-throughput sequencing and mutation sites of the proband and his parents were validated by Sanger sequencing. The proband was diagnosed with Okihiro syndrome, which is characterized by bone abnormality in the arms and hands (radial ray malformation, absence of thumbs) and sensorineural hearing loss. A pathogenic heterozygous c.3060delG variant was identified in exon 4 of spalt-like transcription factor 4 (SALL4) gene in the proband. This is a frameshift mutation that changes increases the length of SALL4 protein from 1,053 to 1,076 amino acids. The variant was classed as a de novo mutation because the parents of the proband showed no variation at this site. This variant is not included in the ClinVar database and, to the best of our knowledge, has not previously been reported. The de novo heterozygous c.3060delG variant was the molecular pathological cause of Okihiro syndrome in the present study and expanded the database of known SALL4 variants.
\end{abstract}

Correspondence to: Dr Jing Ma, Department of Otolaryngology, Head and Neck Surgery, Kunming Children's Hospital, 288 Qianxing Road, Xishan, Kunming, Yunnan 650228, P.R. China

E-mail: majing@etyy.cn

${ }^{*}$ Contributed equally

Abbreviations: DRRS, Duane-radial ray syndrome; ZFM, zinc finger motif; $\mathrm{KCH}$, Kunming Children's Hospital; ABR, auditory brain stem response; $\mathrm{CNV}$, copy number variation; HGMD, Human Gene Mutation Database; NMD, nonsense-mediated decay

Key words: Okihiro syndrome, DRRS, spalt-like transcription factor 4

\section{Introduction}

The human spalt-like transcription factor 4 (SALL4; OMIM no. 607343) gene was cloned and named by Kohlhase et al (1). It is located on chromosome 20q13.2 and consists of 3,162 bp and four exons (2). The protein consists of 1,053 amino acids. SALL4 is a transcription factor that is widely expressed in the early stage of embryo development (3). It is a master regulator that contributes to the growth and differentiation of cancer stem cells (4). Homozygous loss-of-function SALL4 mutations are embryo lethal. The SALL4 protein has multiple zinc finger motifs (ZFMs) of the $\mathrm{C} 2 \mathrm{H} 2$ type. The fragments near the amino and carboxyl terminals each encode one ZFM, while the middle fragment encodes two ZFMs (5). These ZFMs serve an important role in maintaining protein function (6). Variants of SALL4 cause Okihiro syndrome [also known as Duane radial-ray syndrome (DRRS); OMIM no. 607323], which is an autosomal dominant genetic disease (7). Okihiro syndrome was first discovered by Okihiro et al (8) in 1977. This syndrome is characterized by radial malformation associated with the Duane anomaly, which is defined as a limitation of abduction and narrowing of the palpebral fissure with retraction of the globe on adduction (7). Patients with Okihiro syndrome exhibit different degrees of radial line hypoplasia and other types of deformity, which include hypoplasia of the thenar, radius and forearm, spinal and external ear deformity, hearing impairment and heart and kidney abnormality (9-11). SALL4 is highly expressed in the developing midbrain, branchial arch and limbs in healthy individuals, but also serves an important role in the development of skeletal and ocular structures associated with Okihiro syndrome $(1,12)$. The present study investigated the clinical characteristics of a case of Okihiro syndrome. Gene sequencing and bioinformatics analysis were performed to determine whether a SALL4 variant was the molecular cause of the syndrome.

\section{Materials and methods}

Case data. The proband was from Yunnan, China, had profound congenital sensorineural deafness and went to the hospital in July 2020. He received a cochlear implant from Kunming Children's Hospital (KCH). Clinical data from the proband (male, 23 months old) and his father (28 years old) and 
mother (29 years old) were collected via questionnaires. The patient underwent examination of audiology, ophtalmology, hair, skin, limb joints, blood and digestive system. Otoacoustic emission, acoustic immittance, auditory brain stem response (ABR), multiple steady-state response and verbal hearing aid tests were performed to assess audition of the proband. In addition, temporal CT and cranial MRI scans were also performed prior to cochlear implant. Other routine imaging examinations were performed on the patient: These included color duplex ultrasonography of the liver, bile, pancreas, spleen and kidney, in addition to cardiac ultrasonography and brain MRI. Genetic diagnoses were performed with consent from the proband and his parents. The present study was approved by the Medical Ethics Committee of $\mathrm{KCH}$.

DNA library preparation. Genomic DNA was extracted from proband and his parents whole blood $(3 \mathrm{ml})$ using QIAamp DNA Mini kit (Qiagen GmbH), in accordance with the manufacturer's instructions. DNA was quantified using Nanodrop 2000 (Thermo Fisher Scientific, Inc.). A total of $\geq 3 \mu \mathrm{g}$ DNA was used for the indexed Illumina libraries, in accordance with the manufacturer's instructions (Generic DNA Library preparation Kit v5.0; cat. no. MG0126; MyGenostics, Inc.). DNA fragments 350-450 bp in length and included adapter sequences were selected for DNA libraries. The final libraries were qualified using an Agilent 2100 Bioanalyzer system using the Agilent High Sensitivity DNA kit (cat. no. 5067-4626).

Whole-exome sequencing. Before sequencing, the molar mass of the library was calculated according to its concentration and fragment size from the 2100 Bioanalyzer system, using the formula as following: Library molar concentration $(\mathrm{nM})=$ Library concentration $(\mathrm{ng} / \mu \mathrm{l}) \times 10^{6} / 656.6 \times$ Length The loading concentration of the final library was 2 pmol. The enriched libraries were sequenced on NovaSeq6000 sequencer (Illumina, Inc.) using NovaSeq6000 S4 Reagent Kit v1.5 (300 cycles; cat. no. 20028312) to obtain paired-end reads with a length of $150 \mathrm{bp}$.

Data analysis and interpretation. The output data from Illumina NovaSeq were converted from bcl to fastq files by Bcl2Fastq software (Bcl2Fastq 2.18.0.12; Illumina, Inc.). Both Illumina sequencing adapters and low-quality reads ( $<80 \mathrm{bp}$ ) were filtered using fastp (13). The clean reads were mapped to the UCSC hg19 human reference genome using BWA software (v0.7.12-r1044; http://bio-bwa.sourceforge. net/) (14). The duplicated reads were removed using Picard (v2.2.3; http://broadinstitute.github.io/picard/) and mapped reads were used for the detection of variants. Single nucleotide polymorphism (SNP) and insertion/deletion variants were detected using HaplotypeCaller from the GATK software (v4.1.4.0; https://software.broadinstitute.org/gatk/). The data were converted to VCF format. Variants were annotated using ANNOVAR software (16 Apr 2018; http://annovar. openbioinformatics.org/en/latest/). Multiple databases, including 1000 Genomes (201508 collection v5b), ESP6500 (esp6500siv2), dbSNP (dbSNP150), EXAC (http://exac. broadinstitute.org/) and Human Gene Mutation Database (HGMD, http://www.hgmd.cf.ac.uk/ac/index.php) were used to annotate variants to estimate their frequency. Variants were predicted using SIFT (http://provean.jcvi.org/index. php), PolyPhen-2 (http://genetics.bwh.harvard.edu/pph2/), MutationTaster (http://www.mutationtaster.org/) and GERP++ (http://mendel.stanford.edu/SidowLab/downloads/gerp/). Both the CNVKit (CNVkit 0.9.8 documentation) and the delly software (v0.9.1; www.korbel.embl.de/software.html) were used to call copy number and structural variation across all regions. Candidate copy number variations (CNVs) were annotated by analyzing the genes contained in the CNVs and the CNV intervals themselves with the databases Decipher (v11.9, https://decipher.sanger.ac.uk/), dbVar (http://www.ncbi. nlm.nih.gov/dbvar), ClinGen (https://www.clinicalgenome. org/), and OMIM (http://www.ncbi.nlm.nih.gov/omim). The candidate CNVs were then filtered using the normal frequency databases, such as DGV (http://dgv.tcag.ca/dgv/app/home) and gnomAD (https://macarthurlab.org/2017/02/27/the-genomeaggregation-database-gnomad/). CNVs carried by the normal population that are not pathogenic were filtered out to look for rare CNVs which may being pathogenic. Each database had the size of the pathogenic CNVs and is automatically updated. The variants were interpreted in accordance with the American College of Medical Genetics and Genomics guidelines (15) and patient phenotype.

Sanger sequencing. Venous blood $(3.5 \mathrm{ml})$ was collected form the proband and his parents. Genomic DNA was extracted using QIAamp DNA Mini kit (Qiagen $\mathrm{GmbH}$ ) and used for Sanger sequencing. The data from high-throughput sequencing were used to design primers for suspected pathological variants using PRIMER3 (version 0.4.0, https://bioinfo.ut.ee/primer3-0.4.0/), (forward, 5'-CGTGATTGTAGCACTTGCCTG-3' and reverse, 5'-GAATGTGGACCCTGTTGTGTG-3'). PCR was performed using KAPA 2G Fast PCR kit (Roche, cat. no. KK5009), as follows: Initial denaturation at $95^{\circ} \mathrm{C}$ for $5 \mathrm{~min}$, followed by 32 cycles of denaturation at $94^{\circ} \mathrm{C}$ for $30 \mathrm{sec}$, annealing at $60^{\circ} \mathrm{C}$ for $30 \mathrm{sec}$ and extension at $72^{\circ} \mathrm{C}$ for $45 \mathrm{sec}$ and final extension at $72^{\circ} \mathrm{C}$ for $5 \mathrm{~min}$. PCR products (length, $412 \mathrm{bp}$ ) were analyzed by gel electrophoresis and purified. Capillary electrophoretic sequencing was performed using an ABI PRISM 3730 sequencer (Thermo Fisher Scientific, Inc.) and variants were analyzed. The Sanger sequencing results were aligned with SALL4 reference sequence (NM_020436, https://www. ncbi.nlm.nih.gov/nuccore/NM_020436) using SeqMan 7.1 software (16).

Protein structure prediction. The amino acid sequence of SALL4 was obtained from National Center for Biotechnology Information. The structure of SALL4 protein and mutant was predicted using zhanglab.dcmb.med.umich.edu/I-TASSER website. Spbdv (https://spdbv.unil.ch/) was used to visualize and label the results of the I-TASSER predictions.

\section{Results}

Clinical features of proband with Okihiro syndrome. The proband (Table I) was a 23-month-old boy of Han nationality (height, $86.5 \mathrm{~cm}$; weight, $12.0 \mathrm{~kg}$ ) who presented to $\mathrm{KCH}$ because he was born deaf. The patient was severely affected (Table II): Both hands flexed to the radial side and he had 
Table I. Sociodemographic information of the proband.

\begin{tabular}{lc}
\hline Characteristic & Description \\
\hline Sex & Male \\
Age & 23.0 months \\
Height & $86.5 \mathrm{~cm}$ \\
Weight & $12.0 \mathrm{~kg}$ \\
Cochlear implant & Right ear \\
\hline
\end{tabular}

missing radii and thumbs (Fig. 1A-C). His forearms were short and there was dysplasia of the left humerus. Nasal obstruction without respiratory distress was described. Radiographs of the upper limbs showed that the bilateral radius, first palm and phalanx were absent. The bilateral humerus and ulna were curved, with a slightly short and thick ulna. The junction of the ulna and the humerus did not join correctly (data not shown). The bilateral cochlea and vestibule had not developed and showed cystic changes (Fig. 1D and E). The proband presented with severe bilateral sensorineural hearing loss. Clinical audiological examination showed failed bilateral otoacoustic emission (Fig. 1F and G), auditory steady-state response threshold $>110 \mathrm{~dB}$ hearing level (HL; Fig. 1H) under $500-4,000 \mathrm{~Hz}$ and with bilateral ABR threshold $>95 \mathrm{~dB} \mathrm{HL}$ (Fig. 1I). There was no evidence of Duane abnormality on ophthalmologic evaluation. Abdomen B-scan ultrasounds did not identify any abnormalities. The results of the intelligence developmental assessment were normal except for delayed speech development. Red and white blood cell and platelet counts were normal (data not shown). The proband with the aforementioned clinical manifestations was diagnosed as a probable Okihiro syndrome patient $(1,9)$. Both parents of the patient were healthy and non-consanguineous marriage. There was no genetic history of Okihiro syndrome in the family. The proband received a cochlear implant in his right ear at the KCH on 17 August 2020.

Identification of a de novo SALL4 frameshift mutation. A heterozygous variant, c.3060delG, in exon 4 of SALL4 (NM_020436) was detected in the proband and resulted in a $\mathrm{Gln}(\mathrm{Q})$ to $\mathrm{His}(\mathrm{H})$ (p. Q1020Hfs*57) change at amino acid 1,020, which is a frameshift mutation. Sanger sequencing showed that this site was wild-type in the parents (Fig. 2A and B), which indicated that the variant was a de novo variant of the proband. From the point of the variation (amino acid 1,020), the gene encoded the following amino acids: $R$ V S V Q M W K N Q V L T A F P N T S F T S W K K T R L R S A K G E L A W K E Q C R H S E I S R I C F V $\mathrm{L}$. Translation was then terminated and the resulting mutant protein was 1,076 amino acids in length (Fig. 2C). This variant was predicted to exhibit PVS1_PM4 + PS2 + PM2 pathology, based on ACMG guidelines (15). PVS1_PM4 is a frameshift mutation, which may cause loss of function (15). There were no variants at PS2 locus in the parents of the proband. PS2 variant is a spontaneous variant. The mean of PM2 was variant frequency is extremely low, even was not included in the normal population databases 1,000 Genomes and gnomAD. To the best of our knowledge, this variant site has
Table II. Clinical characteristics of the proband.

Characteristic Description

Upper limb deformity

Both hands flexed to the radial side; absent radii and thumbs; short forearms; dysplasis of the left humerus

Upper limb X-ray

Absent bilateral radius, first palm, and phalanx were absent; curved humerus and ulna; short, thick ulna; poor match between ulna and ulnohumeral joint

Temporal CT Undeveloped bilateral cochlea and vestibule Normal

Ophthalmic assessment Otoacoustic emission assessment Auditory steady-state response Auditory brain stem response Failed $>110 \mathrm{~dB} H \mathrm{HL}$ $>95 \mathrm{~dB}$ HL Abdomen B-scan ultrasound Normal

HL, hearing level.

not previously been reported in the literature or ClinVar database (15). The amino acid sequence at position (p. Q1020) was conserved between multiple homologous species (Fig. 2D). The amino acid variant was located in the final $10 \%$ of the protein (red box; Fig. 2F). The configuration of the mutant SALL4 protein showed multiple changes compared with the wild-type (Fig. 2E and F). Due to the change of the amino acid sequence, the $\alpha$-helix primary structure and $\beta$-sheet, irregular coil and other secondary structures of the mutant protein have been changed, the protein cannot be folded correctly, and the spatial configuration was changed.

\section{Discussion}

Okihiro syndrome is rare, with previous reports indicating that most cases are sporadic $(17,18)$. Poznanski indicated that the familial incidence is $5 \%$ in Okihiro syndrome patients (19). The phenotype of patients with variants in SALL4 is highly variable: Certain patients show the full range of clinical phenotypes, while others exhibit only partial clinical manifestations (11). The phenotypes may be different between patients within a family, which means family members may be mistakenly thought to have two different diseases when phenotypes are considered in isolation (7). Duane anomaly is considered to be one of the primary symptoms of Okihiro syndrome but approximately one third of patients with variant SALL4 do not exhibit this abnormality; in affected families, at least one family member may not have this defect (20). Alves et al (9) showed that five out of 28 patients with variant SALL4 did not exhibit Duane abnormality. Similarly, the proband in the present study did not exhibit Duane abnormality. Patients with Okihiro syndrome 

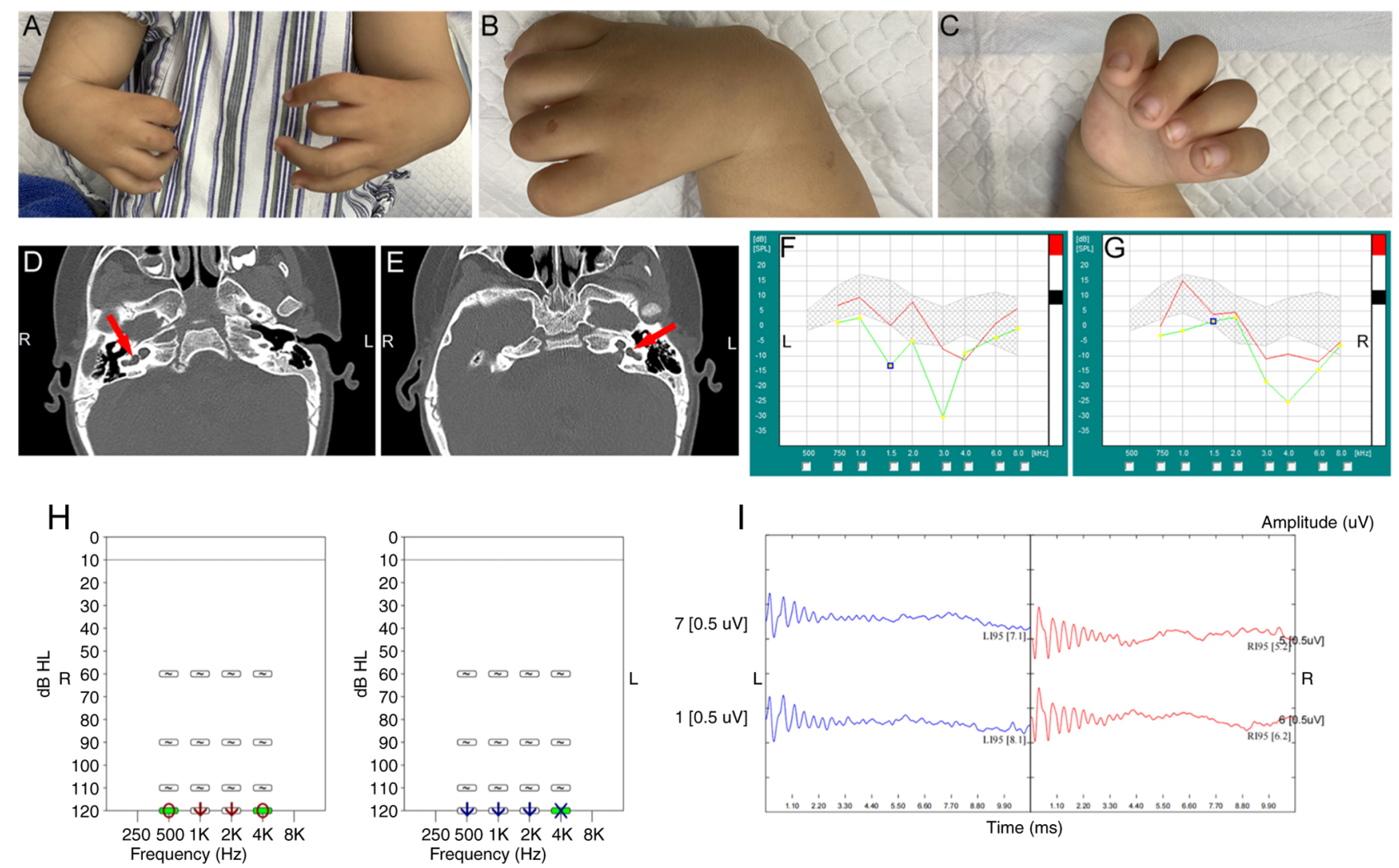

Figure 1. Clinical information of the proband. (A) Both hands were flexed to the radial side. (B) Absence of the thumb. (C) Bilateral radial ray defect. (D) CT, right cochlea and vestibule were underdeveloped and cystic changes (red arrow). (E) CT, left cochlea and vestibule were underdeveloped and cystic changes (red arrow). (F) The left ear fails the otoacoustic emission. (G) The right ear fails the otoacoustic emission. (H) Multiple steady-state response. Auditory steady-state response confirmed profound bilateral congenital sensorineural hearing loss. (I) Auditory brain stem response. Profound bilateral congenital sensorineural hearing loss. CT, computed tomography.

present with upper limb deformity, such as hypoplasia of the thumb, three-phalanged thumb, inward flexion of the radii or absence of the forearm $(7,12)$. In a simple, speculative model, it has been predicted that loss of ZFM domains results in more severe upper limb deformity (5). However, it has also been predicted that truncated protein retains more ZFMs, which leads to a more severe phenotype (21). Therefore, the size of the truncated protein or number of ZFMs does not correspond to the phenotypical severity of upper limb abnormality in the upper limb. Okihiro syndrome causes face, ear, heart, kidney, vertebral body and lower limb abnormality (11). In addition, Parentin et al (22) reported a case of Okihiro syndrome with developmental delay in 2003. The SALL4 missense variant is predicted to result in increased DNA binding affinity and causes Okihiro syndrome with holoprosencephalic features (5). Dental abnormality has also been reported (5). The association of autosomal recessive missense/nonsense variants with mild mental retardation has been demonstrated $(23,24)$. However, mental retardation has not been described in SALL4 genetic syndromes. The phenotype caused by Okihiro syndrome involves multiple systems and certain clinical phenotypes overlap with Townes-Brocks, Holt-Oram, acro-reno-ocular, oculo-oto-radial and cervico-oculo-acoustic syndrome $(7,25)$. Diagnosis of Okihiro syndrome is therefore difficult. As it is rare and certain phenotypical features of SALL4 variant may be due to chance, the syndrome needs to be investigated in further pedigree studies. All affected members of a family should undergo clinical examination to obtain greater understanding of the phenotype of the SALL4 variant.

As of December 2021, HGMD (hgmd.cf.ac.uk/ac/index. php) comprises 53 SALL4 variants associated with Okihiro syndrome. Of these, 40 are point variants (Fig. 3) in exons 2 and 3. The variant site of the present proband was located in exon 4 of SALL4 (Fig. 3); to the best of our knowledge, this is the first variant to be reported in this exon. Only four of the 40 point variants are missense variants; the rest are nonsense/frameshift variants. There are also 13 types of copy number variation of SALL4 that have been included in HGMD (hgmd.cf.ac.uk/ac/index.php). The phenotype of patients with Okihiro syndrome with SALL4 exon deletion is no more severe than the phenotype of patients with point variants (20). To the best of our knowledge, previous case studies have not found a clear association between genotype and phenotype $(1,10,21)$.

Nonsense and frameshift mutations or exon deletions of SALL4 are the primary types of variant that lead to production of truncated proteins (19). Studies have shown that truncated proteins may inhibit the expression of wild-type SALL4 protein in a dominant negative manner $(7,12,26,27)$. The lack of SALL4 protein or production of non-functional ZFMs causes haploinsufficiency, which results in Okihiro syndrome (27). Nonsense-mediated decay (NMD) degrades mRNA of nonsense mutations and decreases accumulation of truncated proteins in the body (28). However, NMD may not effectively eliminate all $S A L L 4$ variants that contain premature stop codons $(29,30)$. SALL4 is only expressed in germ cells in 
A

$1-1$

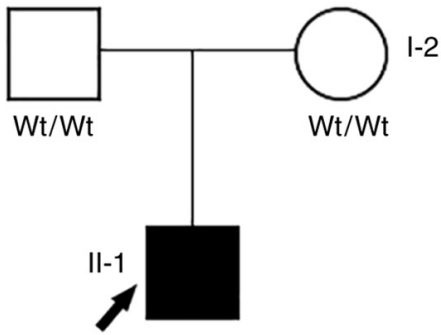

c.3060delG(p.Q1020Hfs*57)
B CTGCACTGATACCCGAGGGACCCTCCCTC

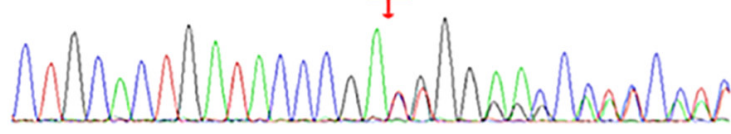

C T GCACTGATACC CG A TGGGAGCCATCCAT

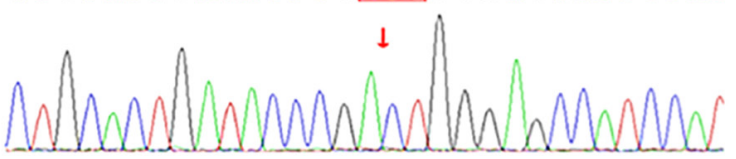

C T GCACT GATACC C GACTGGGAGCCATCCAT

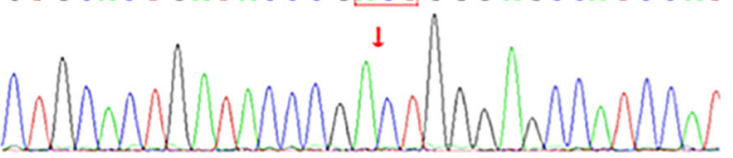

C

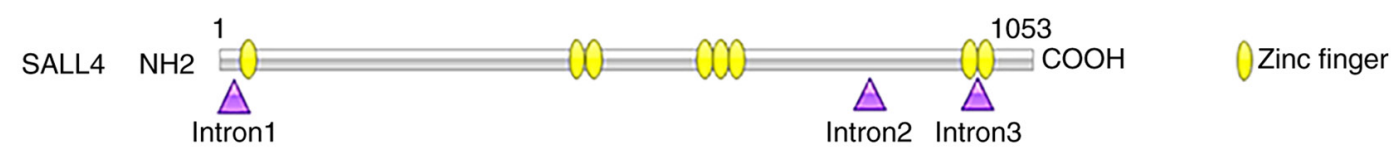

p.Q1020Hfs $57 \mathrm{NH} 2 \stackrel{1}{=}=0$

RVSVQMWKNQVLLTAFPNTSFLTSWKKTRLRSAKGELAWKEQCRHSEISRICFVL

$\mathrm{D}$

Homo sapiens
Pan troglodytes
Macaca mulatta
Canis lupus familiaris
Bos taurus
Mus musculus
Rattus norvegicus
Gallus gallus
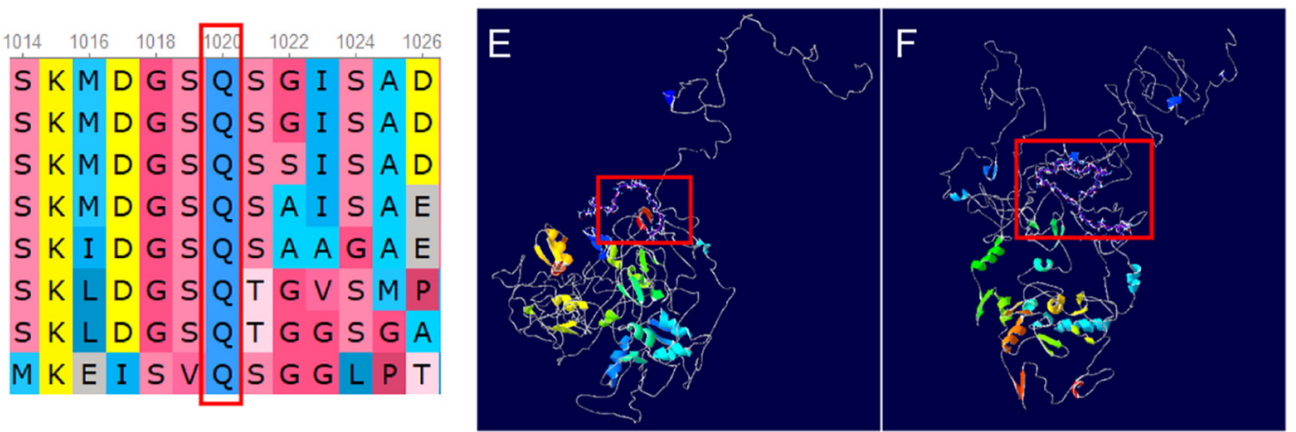

Figure 2. Family pedigree, results of gene sequencing, and bioinformatics analysis. (A) Family pedigree. WT, wild-type; I-1, father of the proband; I-2, mother of the proband; II-1, proband; Q, Gln, glutamine; H, His, histidine; black, patient; white, normal; box, male; circle, female. (B) De novo variant in SALL4 (NM_033326; variant c.3060delG). (C) Schematic representation of SALL4 protein and mutant. (D) Conservation analysis of mutation site. Predicted structure of (E) SALL4 protein and (F) mutant. SALL4, spalt-like transcription factor 4; Wt, wild-type.

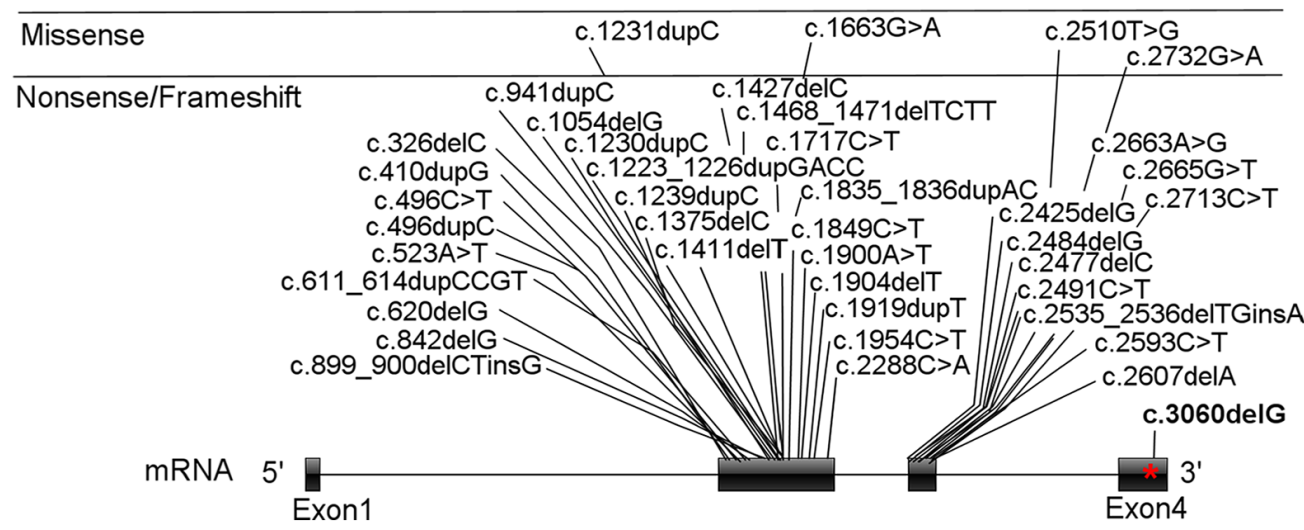

* Mutation site

Figure 3. Schematic representation of spalt-like transcription factor 4 gene and localization of all variants identified. Bold text indicates novel variants reported in the present study.

adult tissue, which hinders the study of the molecular mechanism underlying SALL4-associated limb defect (31). Here, the
SALL4 c.3060delG (p. Q1020Hfs*57) variant did not cause the protein to be truncated. By contrast, the mutant protein was 
longer and the variant was located in the final exon, which did not stimulate NMD. It was hypothesized that the variant sequence at the carboxyl terminal affected configuration of the protein, which caused the Okihiro syndrome.

The current understanding of Okihiro syndrome is not comprehensive and there is no clinical diagnostic standard; further case studies are required to improve clinical understanding and establish a diagnostic standard. However, more attention should be given to the role of genetic testing for rare genetic diseases, which can be accurately diagnosed via genetic testing combined with clinical phenotypes. Okihiro syndrome leads to acral deformities, with upper limb deformity being the most common (21). These deformities may be detected during prenatal check-ups, allowing for early intervention (32).

Sanger sequencing can identify patients with clinical features suspected to be associated with Okihiro/DRRS. To the best of our knowledge, there are few reports on Okihiro syndrome and there may be novel genes that lead to the occurrence of the disease. Whole-exome sequencing may be used to quickly obtain genetic information to diagnose and rule out other potential disease-causing genes (33). Here, a de novo variant of SALL4, c.3060delG (p. Q1020Hfs *57), was the molecular cause of Okihiro syndrome in the proband. Gene sequencing should be used to help clinicians in the diagnosis of rare disease.

\section{Acknowledgements}

Not applicable.

\section{Funding}

The present study was supported by Yunnan Applied Basic Research Joint Special Project of Kunming Medical University (grant no. 202001AY070001-170), Haibo Wang Expert Workstation in Yunnan Province (grant no. 202105AF150056) and Reserve Talents for Young and Middle-aged Academic and Technical Leaders in Yunnan Province (grant no. 2019HB102).

\section{Availability of data and materials}

The datasets used and/or analyzed during the current study are available from the corresponding author on reasonable request.

\section{Authors' contributions}

$\mathrm{XM}$ and RH designed the study, collected data and wrote the manuscript. GL and JM designed the study, analyzed data and wrote the manuscript. JM performed the literature review and revised the manuscript. TZ conceived and designed the study and revised the manuscript. XM and JM confirm the authenticity of all the raw data. All authors have read and approved the final version of the manuscript.

\section{Ethics approval and consent to participate}

The presented study was performed in accordance with the Declaration of Helsinki and approved by The Ethics Committee of Kunming Children's Hospital (Kunming, China, grant no. 2020-01-009-H01). Written informed consent was obtained from all participants.

\section{Patient consent for publication}

The mother of the proband provided consent for publication of images of the proband.

\section{Competing interests}

The authors declare that they have no competing interests.

\section{References}

1. Kohlhase J, Heinrich M, Liebers M, Fröhlich Archangelo L, Reardon W and Kispert A: Cloning and expression analysis of SALL4, the murine homologue of the gene mutated in Okihiro syndrome. Cytogenet Genome Res 98: 274-277, 2002.

2. Kohlhase J, Heinrich M, Schubert L, Liebers M, Kispert A, Laccone F, Turnpenny P, Winter RM and Reardon W: Okihiro syndrome is caused by SALL4 mutations. Hum Mol Genet 11: 2979-2987, 2002.

3. Lim CY, Tam WL, Zhang J, Ang HS, Jia H, Lipovich L, Ng HH, Wei CL, Sung WK, Robson P, et al: Sall4 regulates distinct transcription circuitries in different blastocyst-derived stem cell lineages. Cell Stem Cell 3: 543-554, 2008.

4. Yang J: SALL4 as a transcriptional and epigenetic regulator in normal and leukemic hematopoiesis. Biomark Res 6: 1, 2018.

5. Miertus J, Borozdin W, Frecer V, Tonini G, Bertok S, Amoroso A, Miertus S and Kohlhase J: A SALL4 zinc finger missense mutation predicted to result in increased DNA binding affinity is associated with cranial midline defects and mild features of Okihiro syndrome. Hum Genet 119: 154-161, 2006.

6. de Celis JF and Barrio R: Regulation and function of Spalt proteins during animal development. Int J Dev Biol 53: 1385-1398, 2009.

7. Hayes A, Costa T and Polomeno RC: The Okihiro syndrome of Duane anomaly, radial ray abnormalities, and deafness. Am J Med Genet 22: 273-280, 1985.

8. Okihiro MM, Tasaki T, Nakano KK and Bennett BK: Duane syndrome and congenital upper-limb anomalies. A familial occurrence. Arch Neurol 34: 174-179, 1977.

9. Alves LU,Perez AB, Alonso LG, Otto PA and Mingroni-Netto RC: Novel frameshift variant in gene SALL4 causing Okihiro syndrome. Eur J Med Genet 59: 80-85, 2016.

10. Kohlhase J, Schubert L, Liebers M, Rauch A, Becker K, Mohammed SN, Newbury-Ecob R and Reardon W: Mutations at the SALL4 locus on chromosome 20 result in a range of clinically overlapping phenotypes, including Okihiro syndrome, Holt-Oram syndrome, acro-renal-ocular syndrome, and patients previously reported to represent thalidomide embryopathy. J Med Genet 40: 473-478, 2003.

11. Terhal P, Rösler B and Kohlhase J: A family with features overlapping Okihiro syndrome, hemifacial microsomia and isolated Duane anomaly caused by a novel SALL4 mutation. Am J Med Genet A 140: 222-226, 2006.

12. Sakaki-Yumoto M, Kobayashi C, Sato A, Fujimura S, Matsumoto $\mathrm{Y}$, Takasato M, Kodama T, Aburatani $\mathrm{H}$, Asashima M, Yoshida N and Nishinakamura R: The murine homolog of SALL4, a causative gene in Okihiro syndrome, is essential for embryonic stem cell proliferation, and cooperates with Sall1 in anorectal, heart, brain and kidney development. Development 133: 3005-3013, 2006.

13. Chen S, Zhou Y, Chen Y and Gu J: Fastp: An ultra-fast all-in-one FASTQ preprocessor. Bioinformatics 34: i884-i890, 2018.

14. Li H and Durbin R: Fast and accurate short read alignment with Burrows-Wheeler transform. Bioinformatics 25: 1754-1760, 2009.

15. Richards S, Aziz N, Bale S, Bick D, Das S, Gastier-Foster J, Grody WW, Hegde M, Lyon E, Spector E, et al: Standards and guidelines for the interpretation of sequence variants: A joint consensus recommendation of the American college of medical genetics and genomics and the association for molecular pathology. Genet Med 17: 405-424, 2015.

16. Swindell SR and Plasterer TN: SEQMAN. Contig assembly. Methods Mol Biol 70: 75-89, 1997. 
17. Jourdain AS, Petit F, Odou MF, Balduyck M, Brunelle P, Dufour W, Boussion S, Brischoux-Boucher E, Colson C, Dieux A, et al: Multiplex targeted high-throughput sequencing in a series of 352 patients with congenital limb malformations. Hum Mutat 41: 222-239, 2020.

18. van de Putte R, Dworschak GC, Brosens E, Reutter HM, Marcelis CLM, Acuna-Hidalgo R, Kurtas NE, Steehouwer M Dunwoodie SL, Schmiedeke E, et al: A genetics-first approach revealed monogenic disorders in patients with ARM and VACTERL Anomalies. Front Pediatr 8: 310, 2020.

19. Poznanski AK, Garn SM and Holt JF: The thumb in the congenital malformation syndromes. Radiology 100: 115-129, 1971.

20. Borozdin W, Graham JM Jr, Bohm D, Bamshad MJ, Spranger S, Burke L, Leipoldt $M$ and Kohlhase J: Multigene deletions on chromosome 20q13.13-q13.2 including SALL4 result in an expanded phenotype of Okihiro syndrome plus developmental delay. Hum Mutat 28: 830, 2007.

21. Borozdin W, Wright MJ, Hennekam RC, Hannibal MC, Crow YJ, Neumann TE and Kohlhase J: Novel mutations in the gene SALL4 provide further evidence for acro-renal-ocular and Okihiro syndromes being allelic entities, and extend the phenotypic spectrum. J Med Genet 41: e102, 2004.

22. Parentin F and Perissutti P: Solitary median maxillary central incisor, Duane retraction syndrome, growth hormone deficiency and duplicated thumb phalanx: A case report. Clin Dysmorphol 12: 141-142, 2003.

23. Perez Y, Wormser O, Sadaka Y, Birk R, Narkis G and Birk OS A Rare Variant in PGAP2 causes autosomal recessive hyperphosphatasia with mental retardation syndrome, with a mild phenotype in heterozygous carriers. Biomed Res Int 2017: 3470234, 2017.

24. Scala M, Mojarrad M, Riazuddin S, Brigatti KW, Ammous Z, Cohen JS, Hosny H, Usmani MA, Shahzad M, Riazuddin S, et al: RSRC1 loss-of-function variants cause mild to moderate autosomal recessive intellectual disability. Brain 143: e31, 2020.

25. Paradisi I and Arias S: IVIC syndrome is caused by a c.2607delA mutation in the SALL4 locus. Am J Med Genet A 143: 326-332, 2007.
26. Kiefer SM, McDill BW, Yang J and Rauchman M: Murine Sall1 represses transcription by recruiting a histone deacetylase complex. J Biol Chem 277: 14869-14876, 2002.

27. Kiefer SM, Ohlemiller KK, Yang J, McDill BW, Kohlhase J and Rauchman M: Expression of a truncated Sall1 transcriptional repressor is responsible for Townes-Brocks syndrome birth defects. Hum Mol Genet 12: 2221-2227, 2003.

28. Al-Baradie R, Yamada K, St Hilaire C, Chan WM, Andrews C, McIntosh N, Nakano M, Martonyi EJ, Raymond WR, Okumura $S$, et al: Duane radial ray syndrome (Okihiro syndrome) maps to 20q13 and results from mutations in SALL4, a new member of the SAL family. Am J Hum Genet 71: 1195-1199, 2002.

29. Kiefer SM, Robbins L, Barina A, Zhang Z and Rauchman M: SALL1 truncated protein expression in Townes-brocks syndrome leads to ectopic expression of downstream genes. Hum Mutat 29: 1133-1140, 2008

30. Liberalesso PBN, Cordeiro ML, Karuta SCV, Koladicz KRJ, Nitsche A, Zeigelboim BS, Raskin S and Rauchman M: Phenotypic and genotypic aspects of Townes-Brock syndrome: Case report of patient in southern Brazil with a new SALL1 hotspot region nonsense mutation. BMC Med Genet 18: 125, 2017.

31. Miettinen M, Wang Z, McCue PA, Sarlomo-Rikala M, Rys J, Biernat W, Lasota J and Lee YS: SALL4 expression in germ cell and non-germ cell tumors: A systematic immunohistochemical study of 3215 cases. Am J Surg Pathol 38: 410-420, 2014.

32. Becker R, Horn D, Knoll U, Stumm M, Wegner RD, Peters H and Sarioglu N: First-trimester prenatal diagnosis of Okihiro syndrome. Fetal Diagn Ther 27: 222-226, 2010.

33. Li B, Chen S, Sun K, Xu R and Wu Y: Genetic analyses identified a SALL4 gene mutation associated with holt-oram syndrome. DNA Cell Biol 37: 398-404, 2018.

This work is licensed under a Creative Commons Attribution-NonCommercial-NoDerivatives 4.0 International (CC BY-NC-ND 4.0) License. 